\title{
INVESTIGATION AND ANALYSIS OF TRAVEL TIME VARIABILITY OF SELECTED ROAD INTERSECTION
}

\author{
Thomas Kokumo Yesufu' ${ }^{1}$, Rhoda Omolola Otesile ${ }^{2}$, Temitayo Olutimi Ejidokun', \\ Abiodun Alani Ogunseye ${ }^{4}$ \\ 1,2,4 Department of Electronic and Electrical Engineering, Obafemi Awolowo University, Ile-Ife, Nigeria \\ ${ }^{3}$ Department of Electrical, Electronics and Computer Engineering, Afe Babalola University, Ado-Ekiti, Nigeria
}

Received 29 July 2019; accepted 3 October 2019

\begin{abstract}
This study investigated the dynamic dependence of travel time variability on the route capacity of a monitored road section. This was with a view to providing a better understanding of travel time variability on road sections and, hence, a possible way of dynamically reducing traffic congestion. A typical road intersection was investigated using video method and license plate matching technique. Analysis of travel time distribution on the road axes were conducted during peak periods for five working days. The results obtained indicate that the peak flow rate of traffic was inversely proportional to the degree of variation in travel times, which serve in the ordering and dynamic allocation of times per route of the selected road intersection.
\end{abstract}

Keywords: Travel Time (TT), Travel Time Variability (TTV), traffic congestion.

\section{Introduction}

Transportation plays a crucial role in the growth and development of societies all over the world. Without adequate facilities to move, people, goods and services from one place to another, social and economic activities will be hindered (Biliyamin and Abosede, 2012). Due to increased urbanization and population growth in urban cities, more pressure on traffic flow has been induced. Traffic congestion is a complex multidimensional problem that has continued to defy solutions around the world, especially in developing countries (Achi, 2016). In Nigeria, this is attributed to rapid increase in population and the number of vehicles plying the road network. Furthermore, poor land-use planning and design of road networks has made traffic congestion to become an intractable problem (Raheem et al., 2015).
In a society, traffic congestion leads to increased travel times and costs, which is a main motivation for expanding infrastructure and regulating their use (Fosgerau et al., 2008). Travel time variability (TTV) expresses the degree of variation in the travel time of a trip whenever it is repeated over a period of time under similar conditions (Durán-Hormazábal and Tirachini, 2016). Daily Congestion levels are never the same on the same highway because the varieties of traffic-influencing events that influence congestion are never the same. However, for a reliable traffic system, travelers can anticipate their travel times accurately before their trip, based on the experience of their previous trips, thereby expressing the effectiveness of a freeway (Li, 2004).

The decrease in TTV reduces the uncertainty in decision-making about departure time and

\footnotetext{
${ }^{1}$ Corresponding author: ejidokunto@abuad.edu.ng
} 
the choice of route, thus reducing anxiety and stress caused by such uncertainty (Sun et al., 2003). A high degree of variability indicates that the travel time would be unpredictable making the traffic service less reliable (Turochy and Smith, 2002). Accurate and reliable prediction of travel time helps drivers to make an appropriate decision on the selection of optimal routes and traffic management authorities to efficiently control and manage traffic congestion on a route (Anwar, 2010; Shi et al., 2017; Li et al., 2018).

Intelligent transport system has become a prominent approach for mitigation of congestion using modern information technological gadgets such as vehicle and pedestrian global positioning system (GPS), cameras and other tools to monitor travel speed, time, road-cross section flow and intersection shunt (Wang et al., 2018). Collection of large amount traffic data in real time, provides a holistic understanding of traffic flow and a means of evaluating its status on urban roads. However, the development of appropriate route models that can adapt to stochastic traffic situations and complex road networks will enhance accurate traffic congestion prediction. This will eventually improve the efficiency of traffic and ease its associated problem in urban cities (Omiwale, 2015).

\section{Literature Review}

Eliasson and Sweden (2006) used quantitative methods to forecast travel time variability. They investigated the relationship between congestion levels and travel time variability. Results obtained shows that there is a predictable relationship between the relative standard deviation of travel time and the relative increase in travel time. Peer et al., (2012) developed an econometric model which was used to predict travel time variability for CostBenefit Analysis (CBA). The model was able to explain TTV by the size of mean delays, as well as by other time-variant and invariant road characteristics. The work showed that the resulting relationship between TTV and its explanatory variables can be used in transport-related CBA. Chien and Liu (2012) investigated the measurement of TTV and reliability with Floating Car Data (FCD) which involves the use of statistical formulas for generating suitable reliability indicators such as mean, standard deviation, $95^{\text {th }}$ percentile and buffer index. The result obtained proved that FCD is an applicable tool for collecting travel time.

Durán-Hormazábal and Tirachini (2016) analyzed TTV of cars and public transport trips and estimated the effect of each trip stage on the TTV for complete doorto-door public transport trips, including access, waiting, transfer and in-vehicle time using traffic data from Santiago and Chile. Surveyors performed predetermined trips and recorded each stage for several days between 2007 and 2011, which were complemented by a recorded bus GPS data. The result of the analysis indicated that bus waiting and in-vehicle times are highly significant in explaining total (door-to-door) TTV relative to metro (subway) travel times, whereas walking time is not significant and metro travel time is generally more stable but may be more skewed compared with the travel time of buses on a segregated right-ofway. Furthermore, buses that travel in mixed traffic have not only a larger mean travel time but also a larger variability than buses that travel in bus lanes and segregated bus ways.

Javid and Javid (2018) developed a framework for estimating travel time variability (TTV) 
using a series of robust regression models based on the data from a road in California's highway system during a two-year period. The model was used to estimate highway clearance time and the percent changes in speed for both downstream and upstream sections of the incident bottleneck. Furthermore, travel time variability was estimated based on the proposed speed change models. A micro-simulation of the developed model was carried out which demonstrated that equipping travelers with the estimated travel time variability in case of an incident can improve the total travel time by almost $60 \%$. The results shows that highway shoulder and lane width factor adversely impact downstream highway clearance time.

The aims of this study is to develop a route model for investigating travel time variability using video-based method with license plate recognition technique and also to determine the order and ratio of allocating time to the selected routes by comparing their peak travel time.

\section{Materials and Methods}

\subsection{Description of Study Area}

The study was conducted on selected road segments in Obafemi Awolowo Universiy, Ile-Ife. Figure 1 shows the layout of the road network. Road 2 leads to Road 7, while the later terminates at Ile-Ife Town. Road 7 is the major area of study, due the presence of the Obafemi Awolowo University International School (OAUIS) which was identified as the major cause of traffic congestion. This is can be attributed to vehicles crossing into OAUIS during the morning hour when parents and guardians come to drop their children and wards. It was observed that this congestion often occurs between 7:30am and 8:45am. The $\mathrm{T}$ junction accommodates traffic flow in and out of the OAUIS (Figure 2). A traffic warden is stationed at this point to control traffic in order to ensure efficient flow, however the congestion persists during this period until there is a negligible number of crossings into the OAUIS.

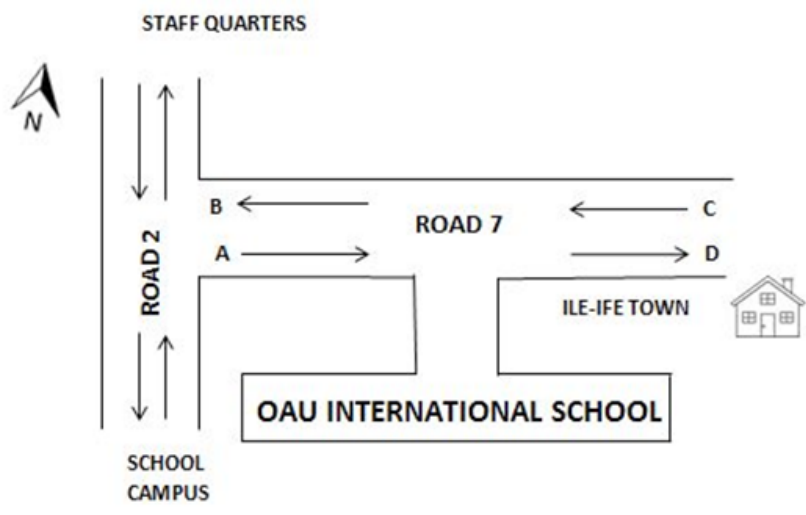

Fig. 1.

Schematic Diagram of the Selected Road Network 


\subsection{Data Collection and Estimations}

The data was collected for a period of five working days, during the peak congestion period between 7:30 am and 8:45 am. Four video cameras were positioned at points $A$, $\mathrm{B}, \mathrm{C}$ and D (Figure 1) to record the flow of traffic across the road sections, with close attention paid to the license plate registration numbers of vehicles commuting the road section. Camera A monitors the traffic coming in from Road 2, B monitors traffic leaving Road 7. Likewise, $\mathrm{C}$ monitors the traffic flow entering Road 7 from Ile-Ife town and $\mathrm{D}$ monitors traffic leaving Road 7 heading towards Ile-Ife town.

Figure 2(a) and (b) shows the schematic model of the study area with point $A$ and $C$ classified as the two major routes. Point $\mathrm{A}$ and $\mathrm{C}$ are separated into three routes each, as illustrated in Equation 1 and 2, using the principle of streamlines and current tubes in conduction fields that is based on the assumption that current cannot flow across a streamline (Shepherd et al., 1986).

$\mathrm{A}=\mathrm{X} 1+\mathrm{X} 2+\mathrm{X} 3$

$\mathrm{C}=\mathrm{Y} 1+\mathrm{Y} 2+\mathrm{Y} 3$

Where,

$\mathrm{X} 1=$ traffic entering from point $\mathrm{A}$ to exit at point D;

$\mathrm{X} 2=$ traffic entering at point $\mathrm{A}$, taking a branch to OAUIS to exit at point D;

$\mathrm{X} 3=$ traffic entering at point $\mathrm{A}$, taking a branch at OAUIS to exit at point B;

$\mathrm{Y} 1=$ traffic entering from point $\mathrm{C}$ to exit at point B;

$\mathrm{Y} 2=$ traffic entering at point $\mathrm{C}$, taking a branch to OAUIS to exit at point $B$;

$\mathrm{Y} 3=$ traffic entering at point $\mathrm{C}$, taking a branch to OAUIS to exit at point $D$.

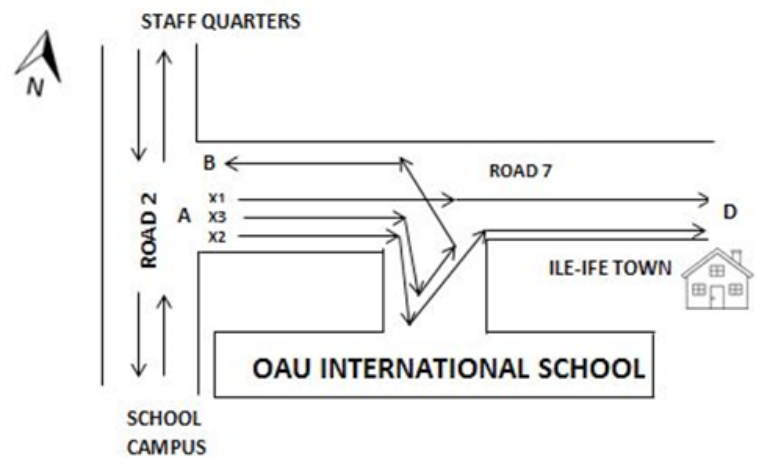

Fig. 2(a).

Schematic Model Showing Separation at Point A 


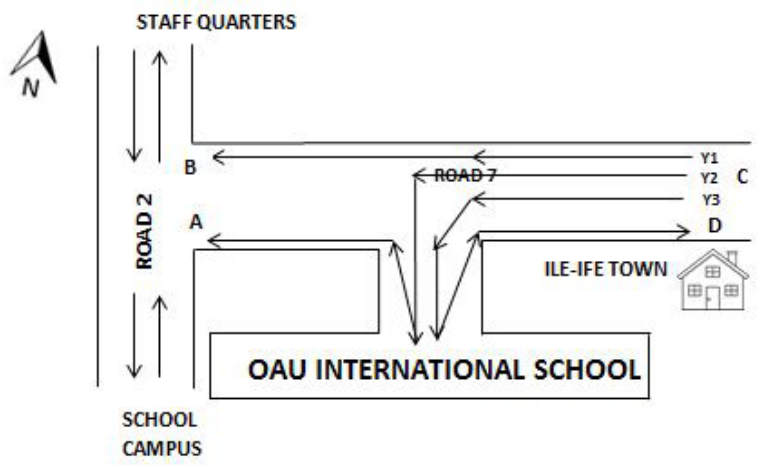

Fig. 2 (b).

Schematic Model Showing Separation of Route at point C

The traffic data needed for analysis are the departure, arrival and computed travel time of vehicles that entering and exiting the route. The travel time in seconds of vehicles plying each route can be calculated using Equation 3, given by:

$\mathrm{TT}=\mathrm{TD}-\mathrm{TA}$

Where,

$\mathrm{TT}=$ Travel time;

$\mathrm{T}_{\mathrm{D}}=$ Departure time;

$\mathrm{T}_{\mathrm{A}}=$ Arrival Time.

Before the commencement of the data collection a test vehicle was used to determine the maximum travel time a vehicle can take in commuting the different routes. It was found that at maximum, a vehicle using $\mathrm{X} 1$ cannot exceed 180 s from entry to exit, on X2-360s, X3-360s, Y1-180s, Y2-420s and $Y 3-420$ s. A vehicle whose travel time exceeds the maximum stipulated travel time for any of the classified route is assumed to be lost, meaning that the vehicle did not exit the route during the period of under observation. The degree of variation in travel time is categorized based on the collected data. A route is considered to have a low travel time variability, whenever the travel time is less than 60 s and high travel time variably once it is greater than 60 s.

\section{Results and Discussion}

\subsection{Analysis of Travel Time along Route $X$ and $Y$}

The analysis of travel time of the six routes for a period of five days between 7.30 a.m.8.45 a.m. is hereby presented. Figure 3(ae) shows graph of TTV of vehicles that travelled on route $\mathrm{X} 1$ for the periods and days under investigation. It was observed that Vehicles which passed through this route on day two and day four started experiencing a consistently high travel time around 7:45:00am which is earlier when compared to days one, three and five that occurred at around 7:51:00am. We can therefore say that route $\mathrm{X} 1$ has high travel time variability with the possibility of peak travel time above 60 s that can occur between 7:45:00am and 8:02:00am on this route. 


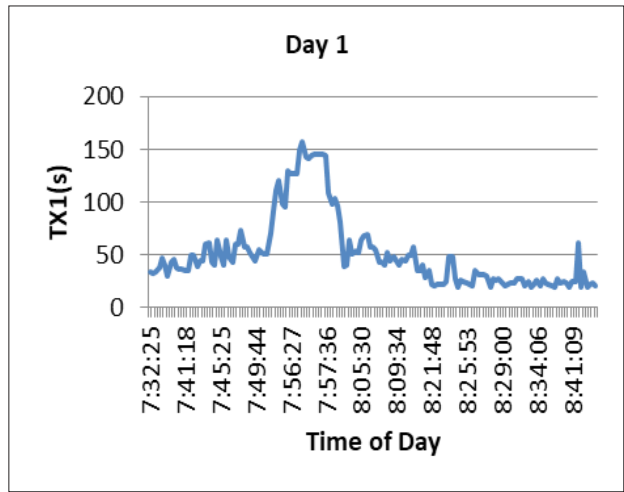

(a)

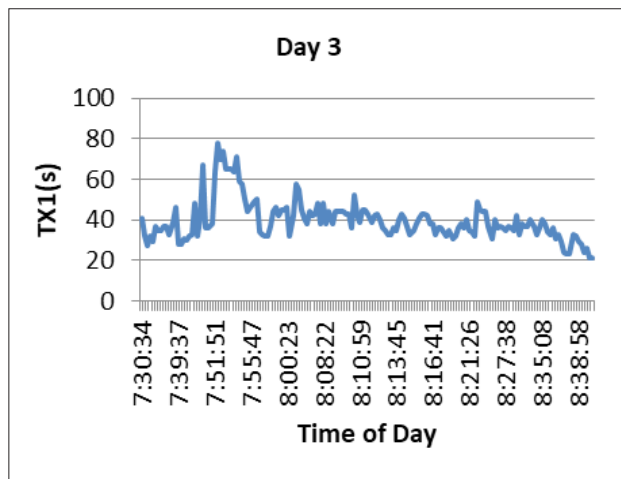

(c)

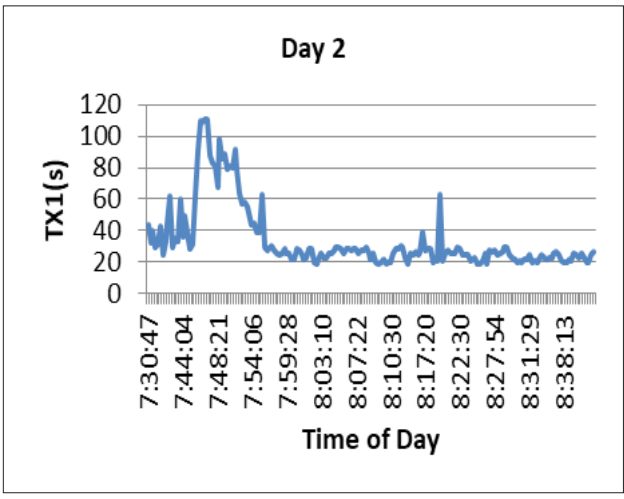

(b)

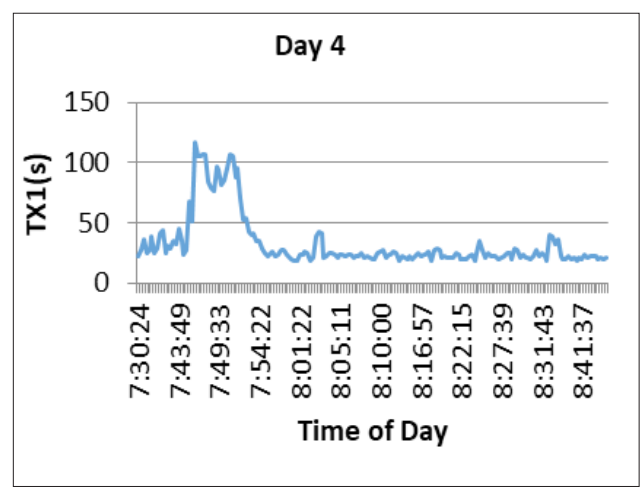

(d)

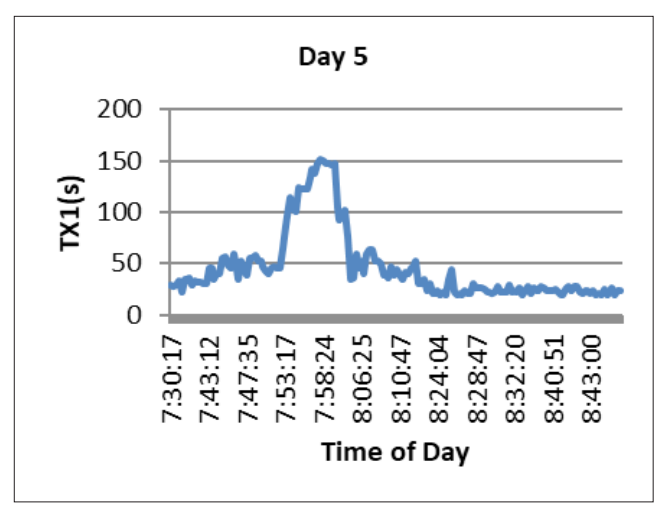

(e)

Fig. 3(a-e).

Travel Time against Time of the Day for Route X1 for Five Days 
Also, in Figure 4(a-e). Vehicles that travelled on day two and day four started experiencing a consistently high travel time consistently around 7:30:00am route $X 2$. Similarly, it was also observed to occur on days one and

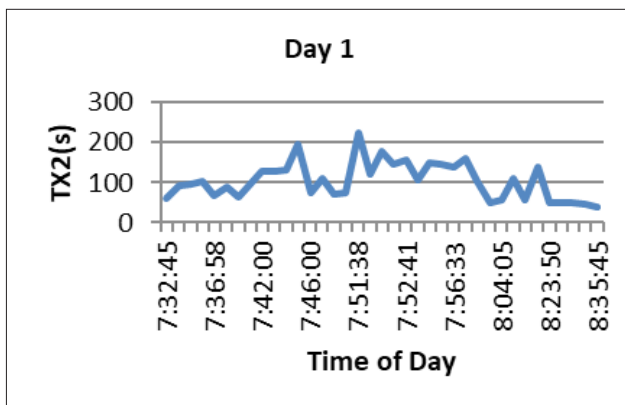

(a)

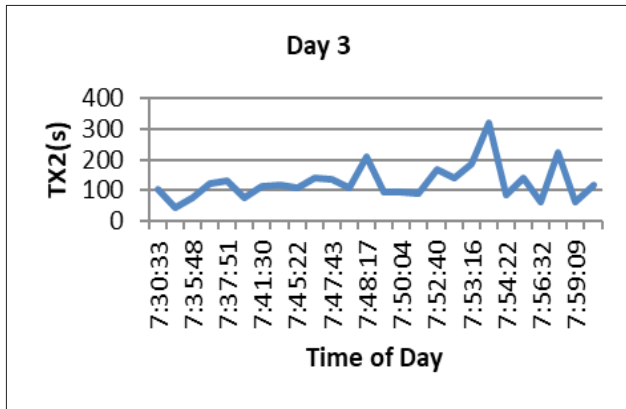

(c) five around 7:32:00am and day three at around 7:35:00am. Route X2 has high travel time variability with the possibility of peak travel time above 60 s occurring between 7:30:00am and 8:04:00am on the route.

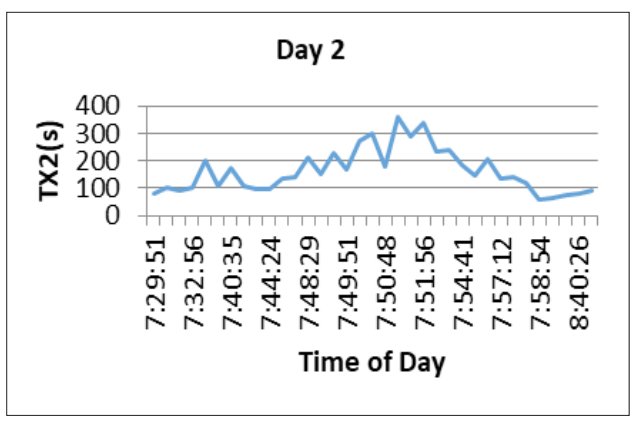

(b)

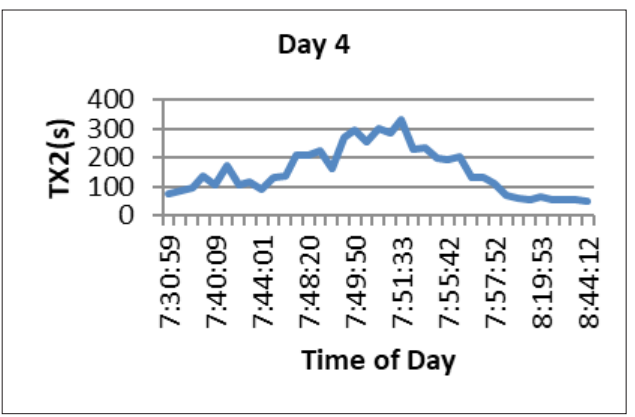

(d)

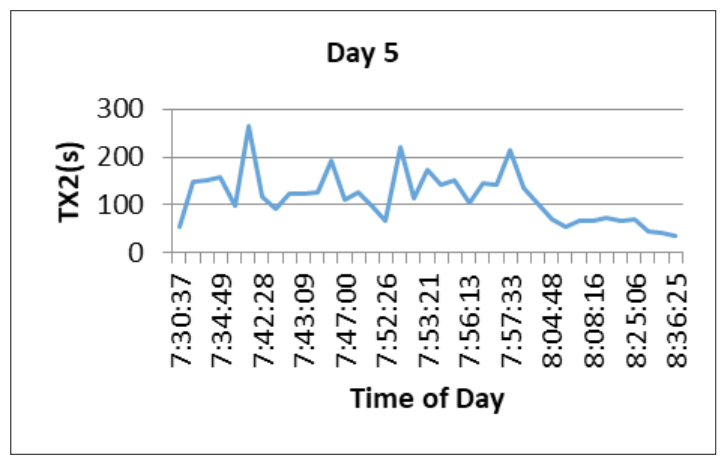

(e)

Fig. 4(a-e).

Travel Time against Time of the Day for Route X2 for Five Days 
From the graphs shown in Figure 5(a-e), consistently, high travel time was experienced earlier on route $\mathrm{X} 3$ for day one from around 7:30:00am, followed by days two, four and five which started at 7:31:00am and day three at 7:32:00am. In summary, route $\mathrm{X} 3$ was highly congested with high travel time consistently witnessed between 7:30:00am and 8:04:00am.

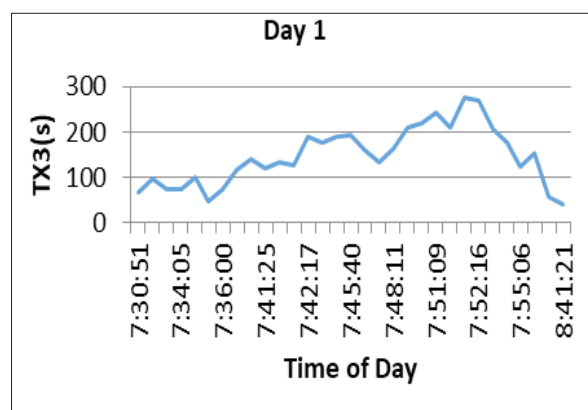

(a)

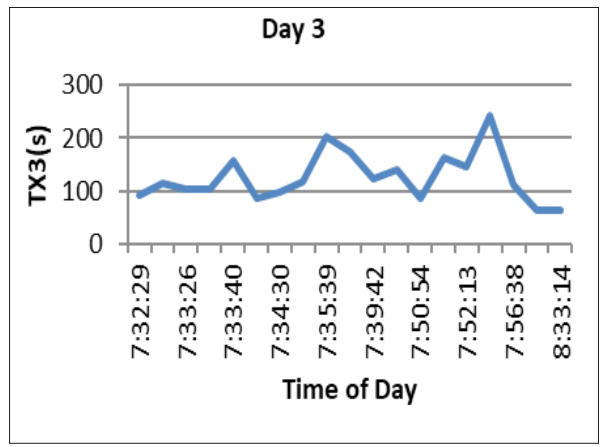

(c)

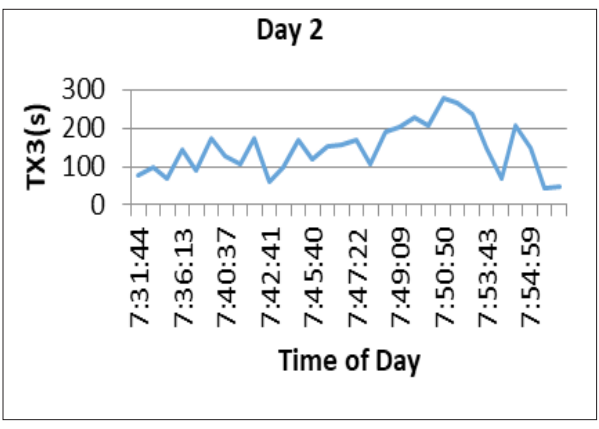

(b)

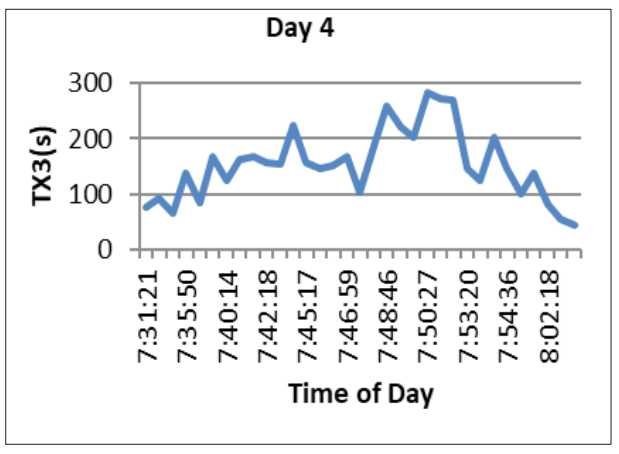

(d)

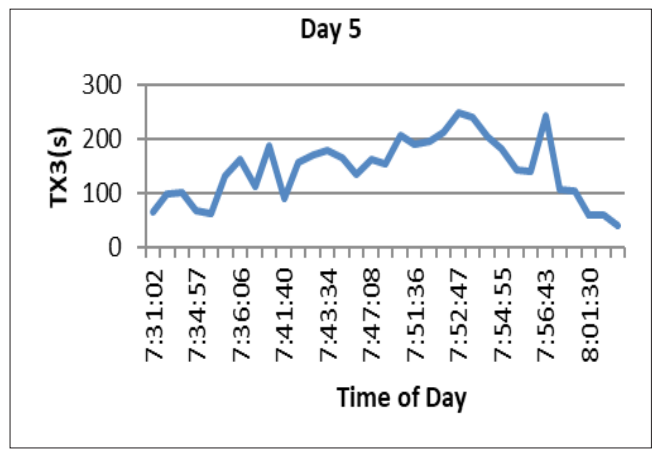

(e)

Fig. 5(a-e).

Travel Time against Time of the Day for Route X3 for Five Days 
In Figure 6(a-e), Route Y1 experienced a consistently high travel time at around 7:43:00 am on day one and day five while day three, day two and day four high travel time was encountered at 7:44:00am, 7:45:00am

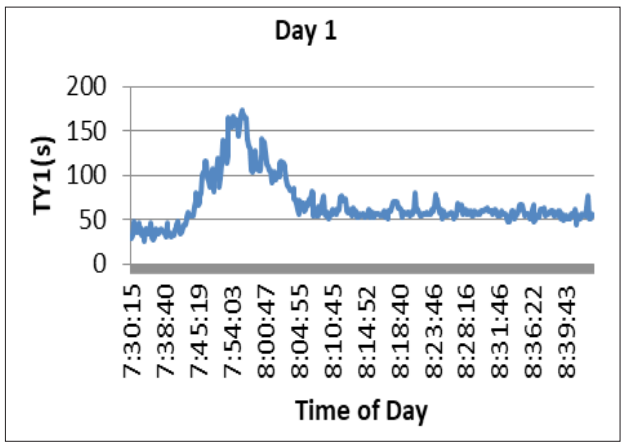

(a)

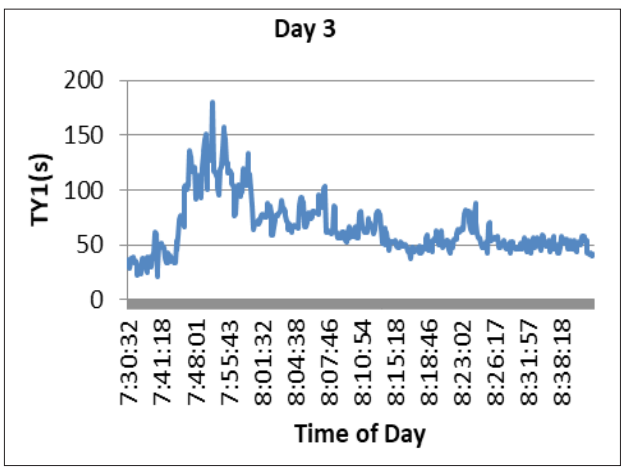

(c) and 7:46:00am respectively. However, it was established that the travel time on Route Y1 is highly variable with very high travel time experienced within the peak period between 7:43:00 am and 8:10:00am.

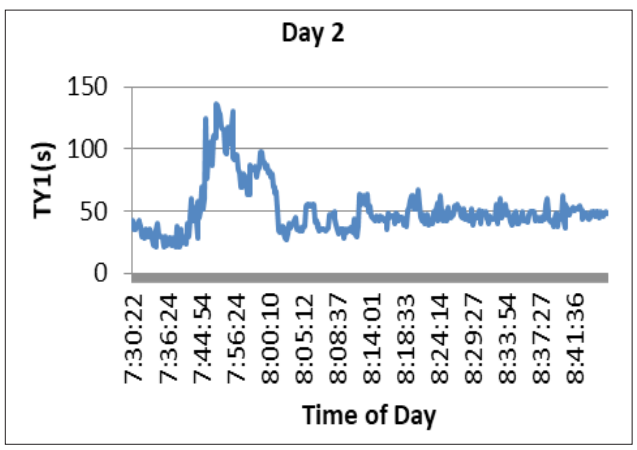

(b)

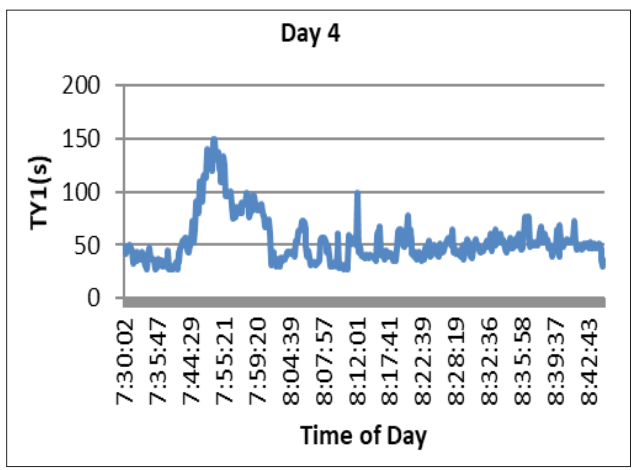

(d)

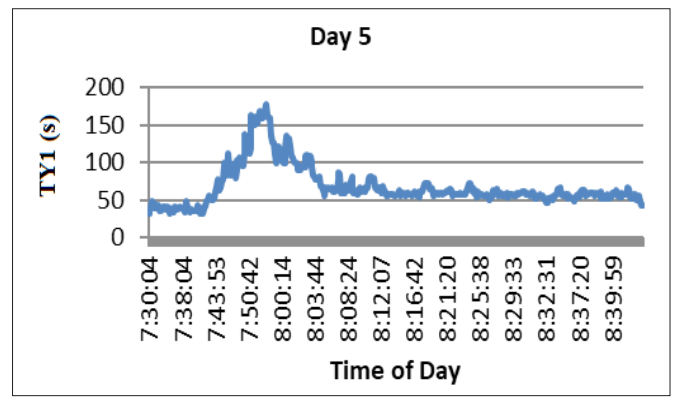

(e)

Fig. 6(a-e).

Travel Time against Time of the Day for Route Y1 for Day One to Day Five 
From the graphs shown in Figure 7(a-e), Vehicles that travelled on day one and day five started experiencing a consistently high travel time at around 7:32:00am while those that travelled on days two and four at around

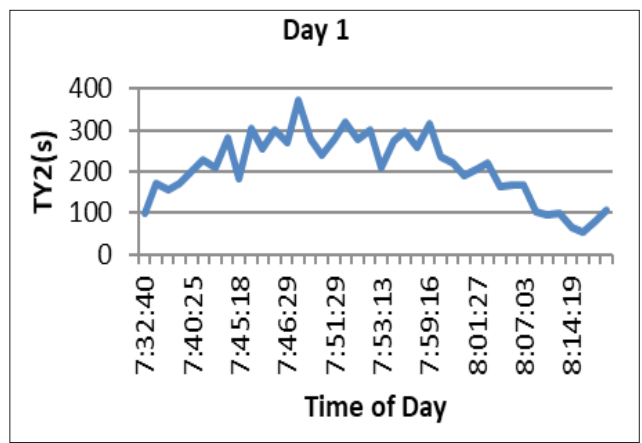

(a)

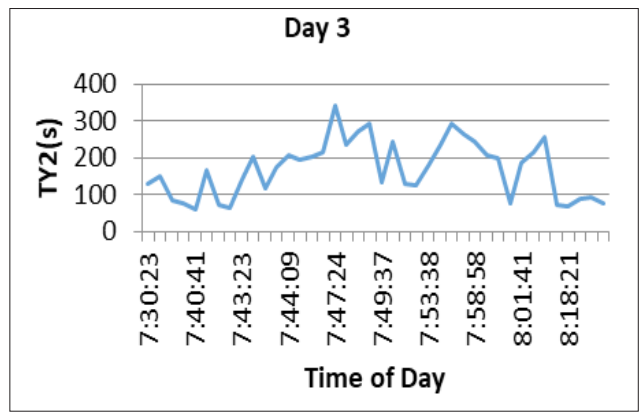

(c) 7:34:00am, and for day three at around 7:41:00am. For all the days, route Y2 was observed to exhibit a high variability in travel time which occurred between 7:32:00am and 8:40:00am.

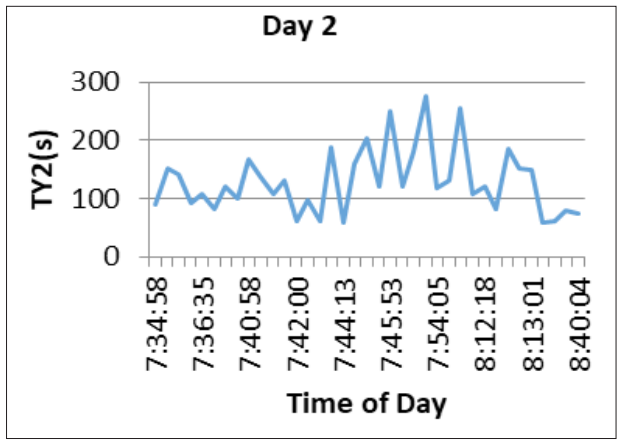

(b)

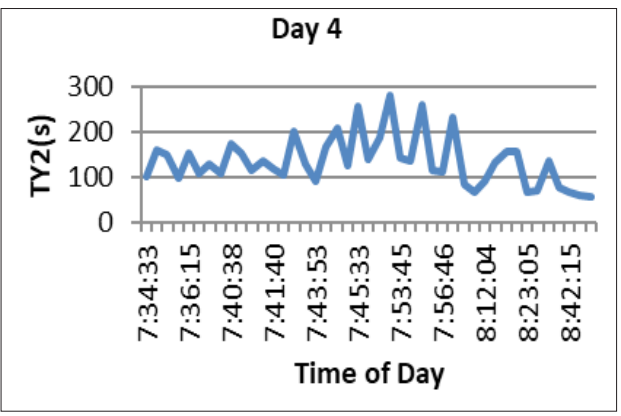

(d)

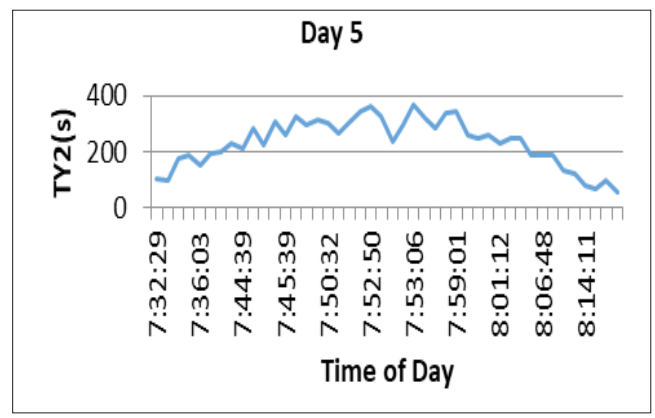

(e)

Fig. 7 (a-e).

Travel Time against Time of the Day for Route Y2 for Day One to Day Five 
A consistently high travel occurred at around 7:30:00am on day four by Vehicles on route Y3 while those that travelled on days one, two and five witnessed it at around 7:31;00 am, and day three at around 7:33:00am as

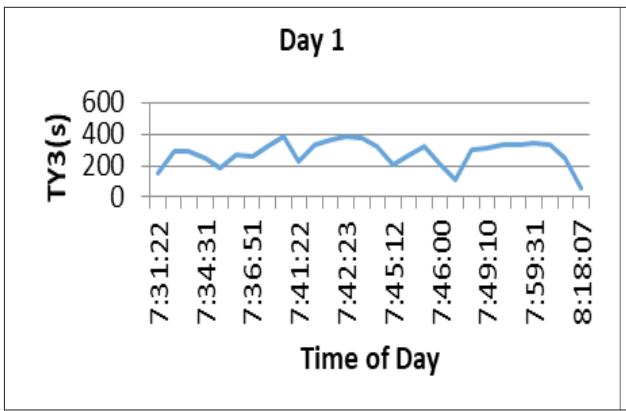

(a)

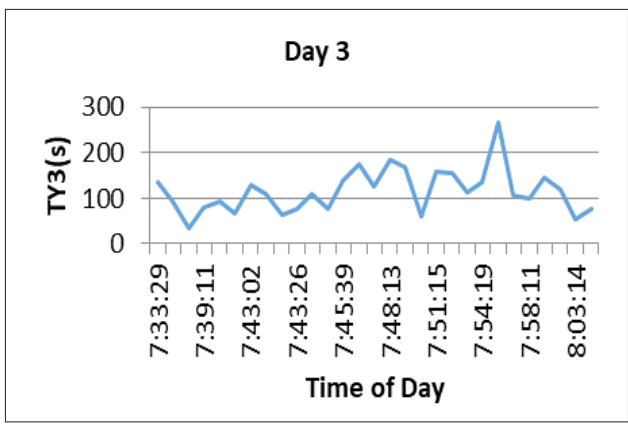

(c) shown in Figure 7(a-e). For all the days, route $\mathrm{Y} 3$ was found to be highly variable in travel time with consistently high travel time above 60 s occurring between 7:30:00am and 8:28:00am daily.

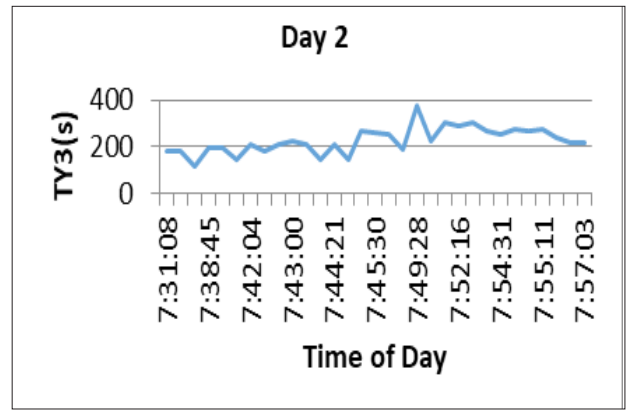

(b)

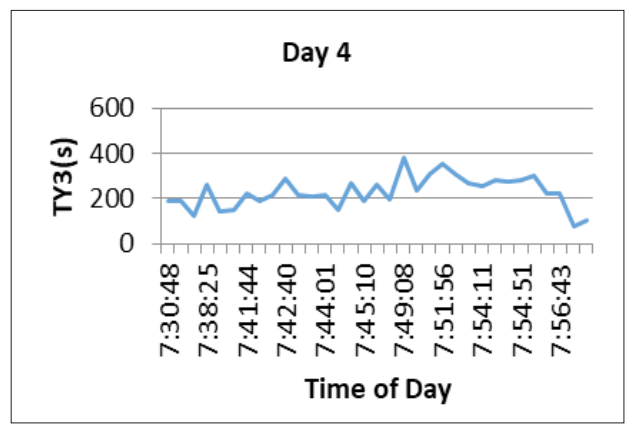

(d)

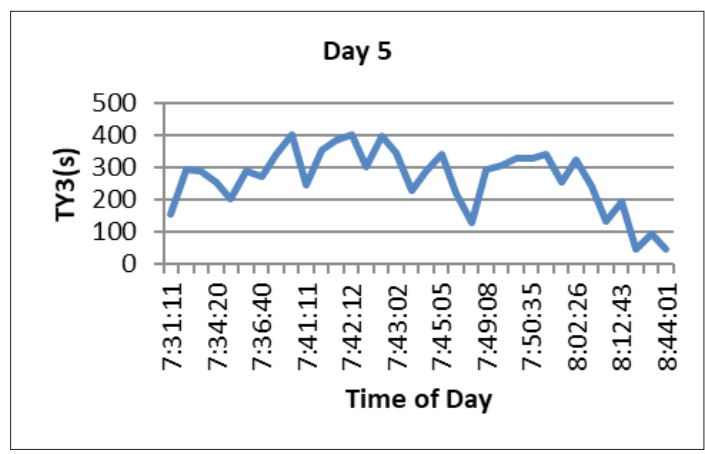

(e)

Fig. 8(a-e).

Travel Time against Time of the Day for Route Y3 for Five Days 


\subsection{Allocation of Time to Routes using Peak Travel Time}

Having carried out a comprehensive investigation and analysis of the pattern of traffic flow for all the routes in five days, there is need to devise a means for quick clearing of congested traffic flow on the routes which will help to reducing travel time of vehicles and decrease the travel time variability on the selected road section. The peak travel time of each route and its corresponding time of occurrence is presented in Table 1. In order to mitigate congestion, specific order, consistent ratio and allocated time for dispersing traffic the specified route was computed using the data presented in Table 1, it was ensured that all the routes in each lanes were served within 180 seconds, as shown in Table 2 .

In Table 2, the order X1:X3:X2 appeared three times with different ratios of allocated ration for dispersing the traffic, it implies that $\mathrm{X} 1$ should be passed first within a duration , followed by X3 and route X2. Similarly, Y3:Y2:Y1 occurred four times, hence, route Y3 should be passed first, followed by Y2 and lastly Y1 while others occurred once. It is observed from the table that the higher the allocated ratio, the greater the time allocated to disperse the traffic, it is attributed to the rise in the peak travel time obtained on those route on the identified days.

\section{Table 1}

Peak Travel Time for Each Route for Five Days

\begin{tabular}{|c|c|c|c|c|c|c|}
\hline ROUTE & $\mathbf{X 1}$ & $\mathbf{X 2}$ & $\mathbf{X} 3$ & Y1 & Y2 & Y3 \\
\hline \multicolumn{7}{|c|}{ DAY 1} \\
\hline Peak time & $7: 56: 47$ & $7: 51: 38$ & $7: 51: 48$ & $7: 56: 32$ & $7: 47: 55$ & $7: 42: 23$ \\
\hline $\begin{array}{c}\text { Peak travel } \\
\text { time }\end{array}$ & 157 & 226 & 277 & 173 & 373 & 386 \\
\hline \multicolumn{7}{|c|}{ DAY 2} \\
\hline Peak time & $7: 46: 17$ & $7: 50: 57$ & $7: 50: 50$ & $7: 52: 04$ & $7: 51: 40$ & $7: 49: 28$ \\
\hline $\begin{array}{c}\text { Peak travel } \\
\text { time }\end{array}$ & 110 & 363 & 277 & 136 & 276 & 376 \\
\hline \multicolumn{7}{|c|}{ DAY 3} \\
\hline Peak time & $7: 52: 31$ & $7: 54: 15$ & $7: 53: 40$ & $7: 52: 33$ & $7: 47: 24$ & $7: 55: 05$ \\
\hline $\begin{array}{c}\text { Peak travel } \\
\text { time }\end{array}$ & 78 & 320 & 243 & 180 & 343 & 267 \\
\hline \multicolumn{7}{|c|}{ DAY 4} \\
\hline Peak time & $7: 45: 41$ & $7: 51: 33$ & $7: 50: 27$ & 7:53:01 & $7: 51: 20$ & 7:49:08 \\
\hline $\begin{array}{c}\text { Peak travel } \\
\text { time }\end{array}$ & 117 & 331 & 283 & 149 & 283 & 383 \\
\hline \multicolumn{7}{|c|}{ DAY 5} \\
\hline Peak time & $7: 58: 21$ & $7: 36: 58$ & $7: 52: 47$ & $7: 54: 01$ & $7: 53: 06$ & $7: 42: 12$ \\
\hline $\begin{array}{c}\text { Peak travel } \\
\text { time }\end{array}$ & 152 & 264 & 250 & 163 & 369 & 405 \\
\hline
\end{tabular}


Table 2

Order and Ration of the Routes for Days One to Five

\begin{tabular}{|c|c|c|c|}
\hline \multirow{2}{*}{ DAY } & ORDER & RATIO & $\begin{array}{c}\text { ALLOCATED } \\
\text { TIME in seconds }\end{array}$ \\
\hline \multirow{2}{*}{ ONE } & $\mathrm{X} 2: \mathrm{X} 3: \mathrm{X} 1$ & $1: 2: 1$ & $45: 90: 45$ \\
& $\mathrm{Y} 3: \mathrm{Y} 2: \mathrm{Y} 1$ & $2: 2: 1$ & $72: 72: 36$ \\
\hline \multirow{2}{*}{ TWO } & $\mathrm{X} 1: \mathrm{X} 3: \mathrm{X} 2$ & $1: 3: 3$ & $26: 77: 77$ \\
& $\mathrm{Y} 3: \mathrm{Y} 2: \mathrm{Y} 1$ & $3: 2: 1$ & $90: 60: 30$ \\
\hline \multirow{2}{*}{ THREE } & $\mathrm{X} 1: \mathrm{X} 3: \mathrm{X} 2$ & $1: 3: 4$ & $22: 68: 90$ \\
& $\mathrm{Y} 2: \mathrm{Y} 1: \mathrm{Y} 3$ & $2: 1: 1$ & $90: 45: 45$ \\
\hline \multirow{2}{*}{ FOUR } & $\mathrm{X} 1: \mathrm{X} 3: \mathrm{X} 2$ & $1: 2: 3$ & $30: 60: 90$ \\
& $\mathrm{Y} 3: \mathrm{Y} 2: \mathrm{Y} 1$ & $3: 2: 1$ & $90: 60: 30$ \\
\hline \multirow{2}{*}{ FIVE } & $\mathrm{X} 2: \mathrm{X} 1: \mathrm{X} 3$ & $2: 1: 2$ & $72: 36: 72$ \\
& $\mathrm{Y} 3: \mathrm{Y} 2: \mathrm{Y} 1$ & $3: 2: 1$ & $90: 60: 30$ \\
\hline
\end{tabular}

\section{Conclusion}

The study has developed a route model for analyzing the travel time variability of a typical section of the road which was selected based on its high probability of rapid congestion within a specified period of time. The developed model was separated and classified into different routes while an investigation into the behavioral pattern of traffic flow of each of the route was conducted. However, relevant traffic information such as computed travel time, peak travel time and its corresponding time of occurrence for days under investigation were obtained, they were used to determine the dynamic allocation of times per route and the order in which the congested traffic would be quickly dispersed. The outcome of this study has demonstrated that knowledge of travel time and the principle of how early or late travel times occurs on routes can be used to make quick decisions on the modalities of traffic flow, thereby improving the reliability of road networks. The method can be extended to cover longer periods of traffic on busy road junctions.

\section{References}

Achi, F. T. 2016. The effects of traffic congestion on travel time in Kaduna Metropolis (Published master's thesis). Ahmadu Bello University, Zaria, Nigeria.

Anwar, A. M. 2010. A Study on factors for travel time variability in Dhaka city corporation area, Journal of Bangladesh Institute of Planners 3:53-64.

Biliyamin, I. A.; Abosede, B. A. 2012. Effects of congestion and travel time variability along AbujaKeffi corridor in Nigeria, Global Journal of Research in Engineering 12(3): 35-40.

Chien, S.; Liu, X. 2012. An investigation of measurement for travel time variability, Intelligent Transportation Systems 51(347): 978-953.

Durán-Hormazábal, E.; Tirachini, A. 2016. Estimation of travel time variability for cars, buses, metro and doorto-door public transport trips in Santiago, Chile, Research in Transportation Economics 59: 26-39.

Fosgerau, M.; Hjorth, K.; Brems, C.; Fukuda, D. 2008. Travel time variability: definition and valuation.: Technical University of Denmark, Copenhagen. 89 p. 
Javid, R. J.; Javid, R. J. 2018. A framework for travel time variability analysis using urban traffic incident data, IATSS research 42(1): 30-38.

Li, R. 2004. Examining travel time variability using AVI data. In Proceedings of the Conference of Australian Institutes of Transport Research (CAITR), Melbourne, Victoria, Australia. No. 36-2004.

Li, R.; Rose, G.; Chen, H.; Shen, J. 2018. Effective long term travel time prediction with fuzzy rules for tollway, Neural Computing and Applications 30(9): 2921-2933.

Omiwale, R. O. 2015. Development of a technique for investigating travel time variability of connected vehicles. M.Sc. Thesis, Department of Electronic and Electrical Engineering, Obafemi Awolowo University, Ile-Ife, Nigeria.

Peer, S.; Koopmans, C. C.; Verhoef, E. T. 2012. Prediction of travel time variability for cost-benefit analysis, Transportation Research Part A: Policy and Practice 46(1): 79-90.

Raheem, S. B.; Olawoore, W. A.; Olagunju, D. P.; Adeokun, E. M. 2015. The cause, effect and possible solution to traffic congestion on Nigeria road: A case study of Basorun-Akobo Road, Oyo State, International Journal of Engineering Science Invention 4(9): 10-14.
Shepherd, J.; Marton, A.; Spence, L. 1986. Higher Electrical Engineering (2nd edition.). Pitman Publishing Ltd, Avon, London, 198p

Shi, C.; Chen, B. Y.; Li, Q. 2017. Estimation of travel time distributions in urban road networks using lowfrequency floating car data, ISPRS International Journal of Geo-Information 6(8): 253.

Sun, C.; Arr, G.; Ramachandran, R. P. 2003. Vehicle re-identification as method for deriving travel time and travel time distribution, Transportation Research Record 1826(1): 25-30.

Turochy, R.; Smith, B. 2002. Measuring variability in traffic conditions by using archived traffic data, Transportation Research Record 1804: 168-172.

Wang, Z.; Yu, Y.; Ju, D. 2018. Analysis and prediction of urban traffic congestion based on big data, International Journal on Data Science and Technology 4(3): 100. 